\title{
Cognitive and linguistic factors in reading acquisition
}

\author{
Ludo Verhoeven $\cdot$ Pieter Reitsma $\cdot$ Linda S. Siegel
}

Published online: 13 May 2010

(C) The Author(s) 2010. This article is published with open access at Springerlink.com

Models of the reading process generally describe the relations among the components of reading in skilled readers. In these models, the relations between bottom-up word recognition processes (lower order processes) and top-down comprehension processes (higher order processes) are typically described. In bottom-up models of reading, processing starts with the raw input and passes through increasingly refined analyses until the meaning of the text is grasped. In top-down models, the decisions made at higher levels of processing are used to guide choices at lower levels. Research evidence makes it clear that neither purely bottom-up nor purely top-down models can fully explain the reading process (Rayner \& Pollatsek, 1989; Stanovich, 2000). An interactive model of ongoing top-down and bottom-up processes is therefore needed to imply that the reader uses both graphic and contextual information to grasp the meaning of a text (Perfetti, Landi, \& Oakhill, 2005; Verhoeven \& Perfetti, 2008).

In the process of learning to read, children start out acquiring elementary decoding skills and learn to apply these with greater accuracy and speed. Word recognition subsequently becomes increasingly automatized by direct recognition of multi-letter units and whole words (Reitsma, 1983; Ziegler \& Goswami, 2005). Automatic word recognition enables children to devote their mental resources to the meaning of text rather than to recognizing words, allowing them to use reading as a tool to acquire new concepts and information (Perfetti, 1998; Samuels \& Flor,

\footnotetext{
L. Verhoeven $(\bowtie)$

Behavioural Science Institute, Radboud University Nijmegen, Nijmegen, The Netherlands e-mail: L.Verhoeven@pwo.ru.nl

P. Reitsma

PI Research, Duivendrecht, The Netherlands

L. S. Siegel

University of British Columbia, Vancouver, Canada
} 
1997). It is commonly assumed that both cognitive and linguistic factors have a great impact on reading acquisition and also on reading impairment.

\section{Role of cognitive and linguistic factors in reading acquisition}

From a cognitive point of view, information-processing theories occupy an important position in the study of children's reading development. Research has clearly shown information-processing factors to constrain children's word reading and reading comprehension processing (see Radach, Kennedy, \& Rayner, 2004). To begin with, attention can be seen as a prerequisite for effective reading. There is indeed research evidence showing the importance of attentional top-down control of visual information processing and saccadic eye-movements in reading (e.g., Schuett, Heywood, Kentridge, \& Zihl, 2008). Furthermore, it has been shown that limitations in attention may cause reading problems (Adams \& Snowling, 2001; Purvis \& Tannock, 2000). Besides, perception may also have an impact on children's reading acquisition. As a case in point, research has shown that problems in both auditory perception (cf. Tallal, 2000) and visual perception (Ramus, 2001) may lead to reading problems.

In addition to attention and perception, working memory is one of the aspects of information processing studied most frequently in conjunction with children's reading development (cf. Seigneuric \& Ehrlich, 2005). In studies on the relation between working memory and reading development reported in the literature, the model of Baddeley is often used to describe the operation of working memory (Baddeley, 2003). The model involves two basic aspects where phonological and visual information are briefly and statically retained, namely the phonological loop and the visual sketchpad. The processing of phonological information is thought to have an inner rehearsal aspect (the articulatory loop) which allows the phonological information needed for the processes of word decoding and reading comprehension to be retained longer in memory. Research evidence for the importance of the phonological loop in reading comes from studies in which phonological working memory has been tested by asking children to repeat series of words (e.g., Nation, Adams, Bowyer-Crane, \& Snowling, 1999), series of nonwords (e.g., Gathercole, Willis, Baddeley, \& Emslie, 1994), or sentence completion tasks (Siegel \& Ryan, 1989). A third more central aspect of Baddeley's model is the central-executive system which constitutes the control mechanism to coordinate the storage and processing of basic information. With respect to the relation between the centralexecutive memory functioning of children and reading development, it has been shown that problems switching between different aspects of information-processing can correlate with language development problems (Baddeley \& Della Sala, 1998).

There is general agreement that in the case of alphabetic writing systems the acquisition of literacy involves the rediscovering of the principles of phonological recoding (Ehri, 1999). In the process of understanding written language, children begin with a rough approach of a limited collection of words that have personal meaning to them. Subsequently, they discover the alphabetic principle on the basis of an analysis of familiar words involving their constituent sounds and letters. 
Phonological recoding can be seen as an inductive learning mechanism on the basis of which children learn to crack the code by mapping letters to sounds, even as phonological mediation remains an obligatory component of lexical access which is routinely activated in advanced reading (see Perfetti, 1992). Given the fact that visual word identification consists in making a familiar phonological form connected to an orthographic form, it can be assumed that the quality of phonological processing plays an essential role in children's early understanding of the alphabetic principle (Anthony \& Francis, 2005).

In the literature, word decoding problems are highly associated with problems in phonological awareness. Phonological awareness refers to the understanding of and access to the sound structure of spoken language, that is the consciousness that oral language can be broken down into individual words, and words into phonemes (cf. Wagner et al., 1997). A large body of research has been conducted on the relation between phonological awareness and learning to read. Numerous correlation studies in primarily English speaking countries have shown a substantial relation between measures of phonemic awareness administered to 5-year olds and tests of word recognition and word spelling among the same children in primary school (cf. Swanson, Trainin, Necoechea, \& Hammill, 2003). There is also research evidence from training studies that phonemic awareness can be seen as a critical component in understanding the alphabetic principle (Bus \& IJzendoorn, 1999). Furthermore, strong support has also been provided that lack of phonological awareness can cause difficulties with the acquisition of reading and writing (de Jong \& van der Leij, 2003). Being able to distinguish and identify the different phonemes in a word is part of this awareness. Research in the past decades has provided ample evidence that dyslexic children have problems with phonological awareness and certain other aspects of phonological processing. There is a general agreement that this initial processing deficit has to do with problems in phonological encoding (Snowling, 2000). Poor readers are less precise in phonemic discrimination, they have problems on a variety of phoneme segmentation and awareness tasks (Vellutino, Fletcher, Snowling, \& Scanlon, 2004), and they are slower in rapid naming of objects, digits, and letters (Wolf \& O'Brien, 2001), as well as in producing rhyming words (Lundberg \& Høien, 2001). It can be hypothesized that dyslexia is fundamentally a linguistic problem that involves a deficit in phonological encoding.

The importance of linguistic factors in reading relate even more to reading comprehension processes. In the simple view of reading proposed by Hoover and Gough (1990), reading comprehension is defined as the product of word decoding and listening comprehension. More specifically, it is claimed that the linguistic processes involved in the comprehension of oral language strongly constrain the process of reading comprehension. These reading comprehension processes would include (a) the parsing of sentences into their constituent components; (b) the drawing of inferences to make the relations within and between sentences sufficiently explicit and thereby facilitate the integration of information; and (c) the identification of underlying text structure, such as the propositions within a text (micro structure), and the global gist of a text (macro structure; see Balota, Flores d'Arcais, \& Rayner, 1990). Research has indeed shown both younger and poorer 
readers to have more difficulty with these processes during listening comprehension than older and better readers (e.g., Yuill \& Oakhill, 1991).

Recent longitudinal studies also point out the importance of both cognitive and linguistic factors in reading acquisition. In a study by Muter, Hulme, Snowling, and Stevenson (2004), children were followed across a period of 2 years after elementary school entry. By the end of second grade, the children's reading comprehension could be predicted by their word identification skills, vocabulary skills, and age six linguistic skills. In a longitudinal study by Oakhill, Cain, and Bryant (2003), verbal IQ, vocabulary, inference skills, and monitoring abilities were found to predict the reading comprehension of children in grades three, four, and six. When Goff, Pratt, and Ong (2005) recently related the reading comprehension of children in grades three through five to their word decoding skills, oral language skills, and working memory skills, they found word decoding and oral language skills to be far more important predictors of reading comprehension than working memory. Moreover, de Jong and van der Leij (2002) showed third-grade word decoding, vocabulary, and listening comprehension skill to predict fifth-grade reading comprehension even after third-grade reading comprehension was controlled for. In a recent study by Verhoeven and Van Leeuwe (2008), the roles of word recognition skills, vocabulary skills, and listening comprehension skills in the development of reading comprehension were examined among a representative sample of elementary school children learning to read Dutch. The results showed that the quantity and quality of word representations is essential for word identification processes in reading development to take place. Furthermore, the data showed that a rich vocabulary along with a high level of listening comprehension helps children to become competent in word-to-text integration.

Word decoding, vocabulary, and listening comprehension can thus be seen as critical factors for developing the ability to efficiently build up text models during reading comprehension. Moreover, verbal memory skills play a special role in research on the relationship between language and literacy problems. Given the fact that linguistic knowledge and memory capacity can be seen as highly interdependent, short-term memory tasks can be seen as indirect means of assessing the operation of language-processing mechanisms (MacDonald \& Christiansen, 2002). In previous studies, it was found that short-term memory is often closely related to phonological processing (Gillam \& Van Kleeck, 1996) and of great importance in language and reading processing (Olofsson \& Niedersoe, 1999), whereas verbal short-term memory deficits were found to be characteristic of disabled readers (Farmer \& Klein, 1995; Siegel, 1994).

\section{The present issue}

This issue of Reading and Writing compiles a set of six research-based articles that assess the role of cognitive and linguistic factors in learning to read in a variety of languages. Thus, the findings from the large body of studies on reading acquisition in English are validated from a cross-linguistic point of view. 
In the first article, Davidse, de Jong, Bus, Huijbregts and Swaab discuss cognitive and environmental predictors of early literacy in Dutch. The study aimed to test the impact of home literacy environment (HLE) on literacy skills and the impact of cognitive control mechanisms (short-term memory, inhibition, sustained attention) on the relation between HLE and literacy outcomes. A sample of 228 junior kindergarten children with a native Dutch background participated in the study. An HLE questionnaire was completed by the parents with notes about book sharing frequency and an author recognition checklist as indicator of parental leisure reading habits. In addition, a book-cover recognition test, a vocabulary test, a letter knowledge test, a cognitive capacity test, and cognitive control measure were administered to the children. The results showed that the relationship between home literacy environment and literacy skills was mediated by children's storybook knowledge. Furthermore, it was found that vocabulary and letter knowledge were predicted by book exposure and that the effects of book exposure were similar whatever the level of cognitive control.

In the next article, Netten, Droop and Verhoeven explore cognitive and linguistic predictors of children reading Dutch as a first and second language. In this study, a multi-factor model was constructed in order to predict the development of reading literacy in the upper grades of primary school in the Netherlands for subgroups of 729 first language (L1) learners and 93 s language (L2) learners. In a longitudinal design, the variation in reading literacy development in L1 and L2 from grade 4 to grade 6 was related to children's word decoding, language, mathematics, and nonverbal reasoning skills, reading motivation and self confidence as well as their home reading resources. The results showed that L1 and L2 learners differed in reading literacy skills and in language, mathematics, and reasoning skills. Structural equation modelling showed that the reading literacy development in both L1 and L2 learners could be explained from decoding, language, mathematics, and reasoning skills, as well as their motivation and self-confidence. A striking difference was the fact that home reading resources had an impact on reading literacy in L1 learners but not in L2 learners.

In the follow-up article, Russak and Saiegh-Haddad examine the role of phonological abilities in normal and dyslexic L1 Hebrew and L2 English adult readers. The study examined the relationships between phonological awareness in L1 (Hebrew) and L2 (English) in a group of 30 normal reading and 30 reading disabled Hebrew native speaking college students. First of all, the effect of the lexical status of the stimulus word (real word vs. pseudo-word) and the linguistic affiliation of the target phoneme (whether it is within L1 or L2) on phonological awareness was examined. Therefore, three parallel experimental phonological awareness tasks were developed in both languages, measuring phoneme isolation, full segmentation, and phoneme deletion. Lower levels of phonological awareness were evidenced in the L2 as compared with the L1 group, and in the reading disabled group as compared with the normal reader group. The lexical status of the target word was a reliable factor predicting individual differences in phonological awareness in L2. It was also found, that the linguistic affiliation of the target phoneme was a reliable factor in predicting L2 phonological awareness performance in both reading groups.

In the subsequent article, Paizi, Zoccolotti and Burani examine the role of lexical stress assignment in Italian developmental dyslexia. Given that stress in Italian 
orthography is neither marked nor predicted by rule, stress assignment to polysyllabic words is unpredictable. Stress assignment, especially to low frequency words, has been reported to be a function of stress dominance and stress neighbourhood. In two experimental studies, stress assignment in sixth-grade, skilled and dyslexic readers was examined. In the first experiment, skilled readers were not affected by stress dominance. However, dyslexic children made more stress regularisation errors on low frequency words. In the second experiment, stress neighbourhood affected low frequency word reading irrespective of stress dominance for both skilled and dyslexic readers. Words with many stress friends were read more accurately than words with many stress enemies. The overall conclusion was that both typically developing and developmental dyslexic Italian readers were sensitive to the distributional properties of the language in stress assignment.

In the penultimate article, Coppens, Tellings, Verhoeven and Schreuder address the development of reading vocabulary knowledge in hearing and hearingimpaired readers of Dutch. The primary aim of this cross-sectional study was to examine both the size and the depth of vocabulary knowledge of pupils in grade $3-6$, and in particular the relative reading vocabulary disadvantage of hearingimpaired pupils as compared with their hearing peers. To tap depth of vocabulary knowledge, 394 normal hearing pupils and 106 hearing impaired pupils were presented with a lexical decision task and a use decision task with vocabulary items that are targeted in the upper years of primary school. The results showed striking differences on the two tasks between hearing and hearing impaired children. Hearing-impaired pupils not only knew fewer words, but the lexical data showed that they also knew them less well. This lack of deeper knowledge remained even after hearing and hearing-impaired children were matched on minimal word knowledge.

In the final article, Dahlin examines the effects of a working memory intervention in 57 Swedish children with special needs. This study addressed the issue whether children's working memory could be enhanced by a cognitive training program, and how the training outcomes would relate to their reading development. Next, how differential aspects of working memory are related to children's reading outcomes was explored. The working memory training yielded effects, and these effects appeared beneficial to children's reading comprehension development. Working memory measures were found to be related with children's word reading and reading comprehension. The results show that working memory can be seen as a crucial factor in the reading development of literacy among children with special needs, and that interventions to improve working memory may help children becoming more proficient in reading comprehension.

Acknowledgments All contributions to this issue were presented at the Fifth European Summer School on Literacy Acquisition that took place in August 2008 in Egmond aan Zee, the Netherlands. Each article received external blind reviews in addition to our reviews. For their input as expert reviewers, we gratefully thank Peter de Jong, Kate Nation and Charles Perfetti.

Open Access This article is distributed under the terms of the Creative Commons Attribution Noncommercial License which permits any noncommercial use, distribution, and reproduction in any medium, provided the original author(s) and source are credited. 


\section{References}

Adams, J. W., \& Snowling, M. J. (2001). Executive function and reading impairments in children reported by their teachers as 'hyperactive'. British Journal of Developmental Psychology, 19, 293-306.

Anthony, J. L., \& Francis, D. (2005). Development of phonological awareness. Current Directions in Psychological Science, 14, 255-259.

Baddeley, A. D. (2003). Working memory and language: An overview. Journal of Communication Disorders, 36, 189-208.

Baddeley, A. D., \& Della Sala, S. (1998). Working memory and executive control. In A. C. Roberts \& T. W. Robbins (Eds.), The prefrontal cortex: Executive and cognitive functions (pp. 9-21). New York, NY: Oxford University Press.

Balota, D. A., D’Arcais, G. B. F., \& Rayner, K. (Eds.). (1990). Comprehension processes in reading. Hillsdale, NJ: Lawrence Erlbaum.

Bus, A. G., \& Van IJzendoorn, M. H. (1999). Phonological awareness and early reading: A meta-analysis of experimental training studies. Journal of Educational Psychology, 91, 403-414.

de Jong, P., \& van der Leij, A. (2002). Effects of phonological abilities and linguistic comprehension on the development of reading. Scientific Studies of Reading, 6, 51-77.

de Jong, P., \& van der Leij, A. (2003). Developmental changes in the manifestation of a phonological deficit in dyslexic children learning to read in a regular orthography. Effects of phonological abilities and linguistic comprehension on the development of reading. Journal of Educational Psychology, 25, 22-49.

Ehri, L. C. (1999). Phases of development in learning to read words. In J. Oakhill \& R. Beard (Eds.), Reading development and the teaching of reading (pp. 79-108). Oxford, UK: Blackwell.

Farmer, M. E., \& Klein, R. M. (1995). The evidence for a temporal processing deficit linked to dyslexia: A review. Psychonomic Bulletin \& Review, 2, 460-493.

Gathercole, S. E., Willis, C. S., Baddeley, A. D., \& Emslie, H. (1994). The children's test of nonword repetition: A test of phonological working memory. Memory, 2, 103-127.

Gillam, R. B., \& Van Kleeck, A. (1996). Phonological awareness training and clinical implications. Topics in Language Disorders, 17, 72-82.

Goff, D., Pratt, C., \& Ong, B. (2005). The relations between children's reading comprehension, working memory, language skills and components of reading decoding in a normal sample. Reading and Writing: An Interdisciplinary Journal, 18, 583-616.

Hoover, W. A., \& Gough, P. B. (1990). The simple view of reading. Reading and Writing: An Interdisciplinary Journal, 2, 127-160.

Lundberg, I., \& Höien, T. (2001). Reading disabilities in Scandinavia. In D. P. Hallahan \& B. K. Keogh (Eds.), Research and global perspectives in learning disabilities. Essays in honor of William M. Cruickshank (pp. 109-123). Mahwah NJ: Lawrence Erlbaum.

MacDonald, M. C., \& Christiansen, M. H. (2002). Reassessing working memory: Comment on Just and Carpenter (1992) and Waters and Caplan (1996). Psychological Review, 109, 35-54.

Muter, V., Hulme, C., Snowling, M. J., \& Stevenson, J. (2004). Phonemes, rimes and language skills as foundations of early reading development: Evidence from a longitudinal study. Developmental Psychology, 40, 663-681.

Nation, K., Adams, J. W., Bowyer-Crane, C. A., \& Snowling, M. J. (1999). Working memory deficits in poor comprehenders reflect underlying language impairments. Journal of Experimental Child Psychology, 73, 139-158.

Oakhill, J., Cain, K., \& Bryant, P. E. (2003). The dissociation of word reading and text comprehension: Evidence from component skills. Language and Cognitive Processes, 18, 443-468.

Olofsson, A., \& Niedersoe, J. (1999). Early language development and kindergarten phonological awareness as predictors of reading problems from 3 to 11 years of age. Journal of Learning Disabilities, 32, 464-472.

Perfetti, C. A. (1992). The representation problem in reading acquisition. In P. B. Gough, L. C. Ehri, \& R. Treiman (Eds.), Reading acquisition (pp. 145-174). Hillsdale, NJ: Lawrence Erlbaum.

Perfetti, C. A. (1998). Learning to read. In P. Reitsma \& L. Verhoeven (Eds.), Literacy problems and interventions (pp. 15-48). Dordrecht, The Netherlands: Kluwer.

Perfetti, C. A., Landi, N., \& Oakhill, J. (2005). The acquisition of reading comprehension skill. In M. J. Snowling \& C. Hulme (Eds.), The science of reading: A handbook (pp. 227-247). Oxford, UK: Basil Blackwell. 
Purvis, K., \& Tannock, R. T. (2000). Phonological processing, not inhibitory control, differentiates ADHD and reading disorder. J Am Acad Child Adolesc Psychiatry, 39, 485-494.

Radach, R., Kennedy, A., \& Rayner, K. (2004). Eye movements and information processing during reading. New York, NY: Psychology Press.

Ramus, F. (2001). Dyslexia: Talk of two theories. Nature, 412, 393-395.

Rayner, K., \& Pollatsek, A. (1989). The psychology of reading. New York: Prentice Hall.

Reitsma, P. (1983). Printed word learning in beginning readers. Journal of Experimental Child Psychology, 36, 321-339.

Samuels, S. J., \& Flor, R. (1997). The importance of automaticity for developing expertise in reading. Reading and Writing Quarterly, 13, 107-122.

Schuett, S., Heywood, C. A., Kentridge, R. W., \& Zihl, J. (2008). The significance of visual information processing in reading: Insights from hemianopic dyslexia. Neuropsychologia, 46, 2441-2458.

Seigneuric, A., \& Ehrlich, M. (2005). Contribution of working memory capacity to children's reading comprehension: A longitudinal investigation. Reading and Writing An Interdisciplinary Journal, 18, 617-656.

Siegel, L. (1994). Working memory and reading: A life-span perspective. International Journal of Behavioral Development, 17, 109-124.

Siegel, L. S., \& Ryan, E. B. (1989). The development of working memory in normally achieving and subtypes of learning disabled children. Child Development, 60, 973-980.

Snowling, M. J. (2000). Language and literacy skills: Who is at risk and why? In D. V. M. Bishop \& L. B. Leonard (Eds.), Speech and language impairment in children: Causes, characteristics, interventions and outcome (pp. 245-260). Hove, UK: Psychology Press.

Stanovich, K. E. (2000). Progress in understanding reading: Scientific foundations and new frontiers. New York, NY: Guilford Press.

Swanson, H. L., Trainin, G., Necoechea, D. M., \& Hammill, D. D. (2003). Rapid naming, phonological awareness, and reading: A meta-analysis of the correlation evidence. Review of Educational Research, 73, 407-440.

Tallal, P. (2000). Experimental studies of language learning impairments: From research to remediation. In D. V. M. Bishop \& L. B. Leonard (Eds.), Speech and language impairments in children: Causes, characteristics, intervention and outcome (pp. 131-155). Hove, UK: Psychology Press.

Vellutino, F. R., Fletcher, J. M., Snowling, M. J., \& Scanlon, D. M. (2004). Specific reading disability (dyslexia): What we have learned in the past four decades? Journal of Child Psychology and Psychiatry, 45, 2-40.

Verhoeven, L., \& Perfetti, C. (2008). Advances in text comprehension: Model, process and development. Applied Cognitive Psychology, 22, 293-301.

Verhoeven, L., \& van Leeuwe, J. (2008). Predictors of text comprehension development. Applied Cognitive Psychology, 22, 407-423.

Wagner, R. K., Torgesen, J. K., Rashotte, C. A., Hecht, S. A., Barker, T. A., Burgess, S. R., et al. (1997). Changing relations between phonological processing abilities and word-level reading as children develop from beginning to skilled readers: A 5-year longitudinal study. Developmental Psychology, $33,468-479$.

Wolf, M., \& O’Brien, B. (2001). On issues of time, fluency, and intervention. In A. Fawcett \& R. Nicolson (Eds.), Dyslexia: Theory and best practice (pp. 124-140). London, UK: Whur Publishers.

Yuill, N., \& Oakhill, J. (1991). Children's problems in text comprehension: An experimental investigation. Cambridge, UK: Cambridge University Press.

Ziegler, J. C., \& Goswami, U. (2005). Reading acquisition, developmental dyslexia and skilled reading across languages: A psycholinguistic grain size theory. Psychological Bulletin, 131, 3-29. 